\title{
Noninvasive Ventilation Failure: The Answer Is Blowing in the Leaks
}

Noninvasive ventilation (NIV) is expected to become more and more common in the treatment of acute respiratory failure, ${ }^{1}$ as new fields of application are explored, and evidence of its efficacy is growing. Moreover, NIV avoids some of the complications related to mechanical ventilation and, in particular, to tracheal intubation. ${ }^{2}$

However, there is also an increasing awareness of the complexity of NIV treatment. Success depends on multiple factors not under the control of the clinical staff, such as the cause and severity of the acute respiratory failure and the patient's comorbidities. But success is also strongly influenced by the experience and skill of the healthcare personnel: the choice of the right timing (early!), ${ }^{1}$ the choice of the right ventilator, ${ }^{3}$ and the choice of the right ventilation settings. Above all, in our opinion, is the choice of the right interface and the ability to motivate the patient to keep the mask in place (without moving it to suboptimal, air-leaking positions) despite some discomfort.

As a matter of fact, NIV failure rates as high as $50 \%$ for patients with acute respiratory distress syndrome have been reported, ${ }^{1}$ while a rate as low as $22 \%$ was observed in a mixed population, ${ }^{4}$ and even lower rates in subgroups highly responsive to NIV, such as COPD patients. ${ }^{5}$ How many of these failures are avoidable, and how? The topic is relevant because the mortality rate in patients who fail NIV is reportedly very high.6,7

See the Original Study on Page 1758

In this issue of ReSPIRATORY CARE an elegant study by Ueno and co-workers ${ }^{8}$ offers new insights on potential hidden reasons for NIV failure, and implicitly suggests how to reduce its occurrence. In simulated scenarios, Ueno et al tested the impact of different degrees of air leak on the performance of 3 NIV ventilators and 2 intensive-care ventilators that have NIV modes. The NIV ventilators (but not the intensive-care ventilators) compensated adequately for the low and medium leaks; nevertheless, with the large leak the PEEP and pressure support did not reach the set levels in any of the tested ventilators. Triggering was also negatively affected.

To put these findings into proper perspective, we should know how often and to what extent moderate-to-high air leak interferes with NIV in clinical practice. Air leak is reported as a common problem, ${ }^{9-11}$ but we do not know how frequently leak causes NIV failure. Vignaux et al ${ }^{12}$ reported that the magnitude of leak correlated with the number of ineffective breaths and the severity of delayed cycling, substantially affecting patient comfort. How often is the patient so annoyed as to refuse treatment due to the air leaks around the mask, or by the high air flow generated by the ventilator to compensate for the leaks, or by the triggering malfunctions? And how often do the leaks prevent reaching the set ventilation pressures and thus make NIV ineffective? Simply, we do not know. But we should. Besides, NIV application in ordinary wards is becoming more common, ${ }^{4,5,9,10}$ and in that setting, monitoring of air leaks cannot be as strict as in an intensive care unit, and the consequences of a badly positioned mask could be severe.

On the other hand, we must remember that reducing leak around the mask is not without consequence when the mask is tightened as much as possible. ${ }^{13}$ Although skin lesions due to the mask are probably under-reported, they are an important cause of patient discomfort. A prudent balance between leak and mask pressure on the skin must be achieved every time NIV is applied. This balance should be mainly based on patient comfort, so we must always keep in mind that the time spent listening to the patient and motivating the patient is time well spent. Besides, systematically collecting patients' perspectives on NIV treatment could be a valuable research and quality-improvement tool. What do the findings from Ueno and co-workers mean for our daily practice? We propose 3 considerations.

First, NIV is quite different from invasive mechanical ventilation, and possibly more complex. At the moment, NIV is still more of an art than a science. In his recent paper, Hess described the multiple factors that influence patient-ventilator interaction and proposed some strategies to optimize it. ${ }^{14}$ Success is highly influenced by what inexperienced personnel could consider secondary details ${ }^{14,15}$; among these, to find the best-fitting and besttolerated mask is crucial. NIV efficacy is maximized when it is applied early ${ }^{1}$; this window of opportunity ${ }^{16}$ closes when acute respiratory failure becomes severe, but it also closes abruptly if the patient becomes no longer compliant and refuses the treatment. So, frequently there is a limited available period for NIV, and no room for negligent application. To maximize NIV's effectiveness, the knowledge and experience of the clinicians who prescribe and apply the treatment are key factors. Fully trained NIV 
specialists should be promptly available as soon as NIV is required; expertise in invasive mechanical ventilation is not sufficient. An NIV service offered by a multidisciplinary team of physicians, nurses, and respiratory therapists might be the best system.

Second, a wide variety of ventilators and interfaces should be present. For difficult cases, the choice of a costly, very comfortable mask could be appropriate and cost-effective if it avoids tracheal intubation. The same could be true for specifically designed, sophisticated NIV ventilators.

Third, we know very little about what patients experience when treated with NIV, even if we are well aware of how fundamental patient comfort is to NIV success. ${ }^{17,18}$ Without strict patient cooperation, the daily battle against leaks and skin breakdown is lost. Patients have a lesson to teach us about masks, leaks, pressure support, and inspiratory and expiratory triggering-a lesson not completely available from observation of the patient and the ventilator display.

In the meanwhile, we commend Ueno and co-workers for having added a fundamental clue about potentially avoidable NIV failure factors.

Luca Cabrini MD Giovanni Landoni MD Alberto Zangrillo MD

Department of Anaesthesia and Intensive Care Ospedale Istituto Scientifico San Raffaele Milan, Italy

\section{REFERENCES}

1. Nava S, Hill NH. Non-invasive ventilation in acute respiratory failure. Lancet 2009;374(9685):250-259.

2. Del Sorbo L, Ranieri VM. We do not need mechanical ventilation any more. Crit Care Med 2010;38(10 Suppl):S555-S558.

3. Chatburn RL. Which ventilators and modes can be used to deliver noninvasive ventilation? Respir Care 2009;54(1):85-101.

The authors have disclosed no conflicts of interest.

Correspondence: Luca Cabrini MD, Department of Anaesthesia and Intensive Care, Ospedale Istituto Scientifico San Raffaele, Via Olgettina 60, 20132 Milan Italy. E-mail: cabrini.luca@hsr.it.

DOI: $10.4187 /$ respcare. 01565
4. Cabrini L, Idone C, Colombo S, Monti G, Bergonzi PC, Landoni G, et al. Medical emergency team and non-invasive ventilation outside ICU for acute respiratory failure. Intensive Care Med 2009;35(2): 333-343.

5. Plant PK, Owen JL, Elliott MW. Early use of non-invasive ventilation for acute exacerbations of chronic obstructive pulmonary disease on general respiratory wards: a multicentre randomised controlled trial. Lancet 2000;355(9219):1931-1935.

6. Lefebvre A, Lorut C, Alifano M, Dermine H, Roche N, Gauzit R, et al. Noninvasive ventilation for acute respiratory failure after lung resection: an observational study. Intensive Care Med 2009;35(4): 663-670.

7. Adda M, Coquet I; Darmon M, Thiery G, Schlemmer B, Azoulay E. Predictors of noninvasive ventilation failure in patients with hematologic malignancy and acute respiratory failure. Crit Care Med 2008; 36(10):2766-2772.

8. Ueno Y, Nakanishi N, Oto J, Imanaka H, Nishimura M. A bench study of the effects of leak on ventilator performance during noninvasive ventilation. Respir Care 2011;56(11):1758-1764.

9. Bierer GB, Soo Hoo GW. Noninvasive ventilation for acute respiratory failure: a national survey of Veterans Affair Hospitals. Respir Care 2009;54(10):1313-1320.

10. Cabrini L, Antonelli M, Savoia G, Landriscina M. Non-invasive ventilation outside the intensive care unit: an Italian survey. Minerva Anestesiol 2011;77(3):313-322.

11. Cabrini L, Monti G, Villa M, Pischedda A, Masini L, Dedola E, et al. Non-invasive ventilation outside the intensive care unit for acute respiratory failure: the perspective of the general ward nurses. Minerva Anestesiol 2009;75(7-8):427-433.

12. Vignaux L, Vargas F, Roeseler J, Tassaux D, Thille AW, Kossowsky MP, et al. Patient-ventilator asynchrony during non-invasive ventilation for acute respiratory failure: a multicenter study. Intensive Care Med 2009;35(5):840-846.

13. Dellweg D, Hochrainer D, Klauke M, Kerl J, Eiger G, Kohler D. Determinants of skin contact pressure formation during non-invasive ventilation. J Biomech 2010;43(4):652-657.

14. Hess DR. patient-ventilator interaction during non-invasive ventilation. Respir Care 2011;56(2):153-165, discussion 165-167.

15. Costa R, Navalesi P, Spinazzola G, Ferrone G, Pellegrini A, Cavaliere $\mathrm{F}$, et al. Influence of ventilator settings on patient-ventilator synchrony during pressure support ventilation with different interfaces. Intensive Care Med 2010;36(8):1363-1370.

16. Liesching T, Kwok H, Hill NS. Acute applications of noninvasive positive pressure ventilation. Chest 2003(2):124:699-713.

17. Rocco M, Conti G, Alessandri E, Morelli A, Spadetta G, Laderchi A, et al. Rescue treatment for noninvasive failure due to interface intolerance with remifentanil analgosedation: a pilot study. Intensive Care Med 2010;36(12):2060-2065.

18. Clouzeau B, Bui HN, Vargas F, Grenouillet-Delacre M, Guilhon E, Grudon D, Hilbert G. Target-controlled infusion of propofol for sedation in patients with non-invasive ventilation failure due to low tolerance: a preliminary study. Intensive Care Med 2010;36(10): 1675-1680. 